\title{
THE RAPID DETERMINATION OF LEAD ON FILTER PAPER
}

\author{
Noboru HARA \\ National Institute of Industrial Health, Kizuki-Sumiyoshi, Kawasaki
}

(Received July 13, 1965)

\begin{abstract}
In alkali solution, diphenylcarbazide reacts with lead and produces a water soluble complex of deep red. The author intended to determine lead on the filter paper using this reaction. The fixed volume of lead solution was spotted on the filter paper and was developed with diphenylcarbazide. Then the area of developed spot increased logalithmically with the increasing concentration of lead solution. By this method, $1 \sim 50 \gamma$ of lead can be determined easily and quickly. When the lead solution was spotted on the narrow filter paper $(2 \mathrm{~mm}$ or $4 \mathrm{~mm}$ in width), lead could be determined from the length of colored part. Limit of identification by this method is about 0.01 $\gamma$ lead, and limit of determination is about $0.1 \gamma$ lead.
\end{abstract}

Since the alcoholic solution of diphenylcarbazide reacts with lead compounds and gives a red solution, it can be used for detection of lead.1,2) The author tried to apply this reaction for rapid determination of lead in the lead solution or lead dust captured on the filter paper. ${ }^{3,4)}$

\section{METHOD}

Reagents

Standard lead solution, $0.160 \mathrm{~g}$ of refined lead nitrate in $100 \mathrm{ml}$ of (1:100) nitric acid. Prepare lead solution of various concentration. Dilution should be made before use.

Diphenylcarbazide, $0.8 \%$ solution in ethanol (prepare before use), Ammonium hydroxide, conc., Filter paper, Whatmann No. 1.

\section{Procedure}

One drop of fixed volume $(10 \mu 1$ or $5 \mu 1)$ of lead solution was placed on the filter paper with micropipette, and stood till becamd dry. Diphenylcarbazide solution was sprayed on this paper and dried up. Then the paper was inserted into a chamber which had been saturated with ammonia gas. Red spot appeared. After 45 minutes, the paper was transfered into an oven. In the oven, the paper was dried for about 30 minutes at $130^{\circ} \mathrm{C}$ to remove the retained ammonia gas quickly and thoroughly.

\section{DETERMINATION BY COLORED LENGTH}

When lead solution of $5 \mu 1$ was spotted on narrow paper of $4 \mathrm{~mm}$ or $2 \mathrm{~mm}$ 


\section{N. HARA}

in width and treated by this method, a close correlation was found between the lengths of developed parts and the amounts of lead (Fig. 1).

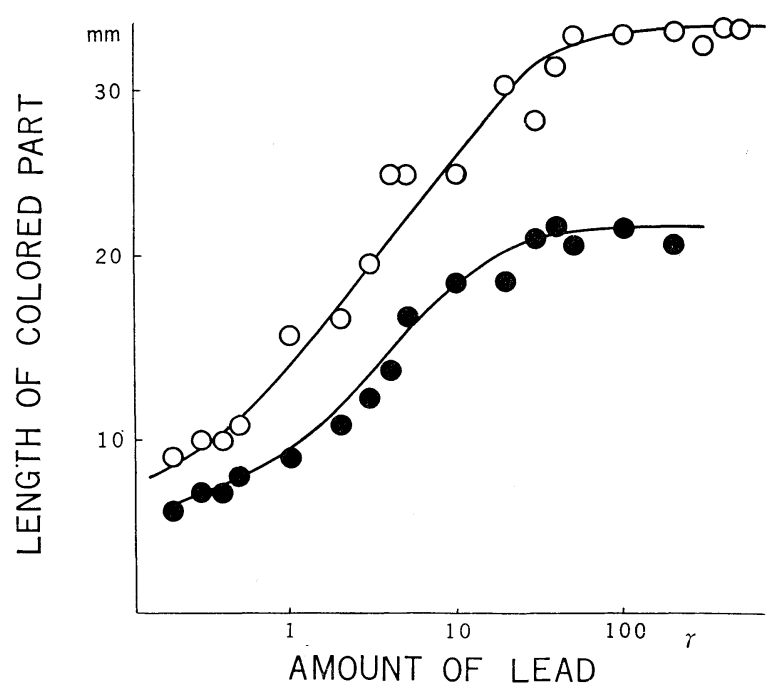

Fig. 1. Relation between the amount of lead and length of colored part.

When the amount of lead exceeded $50 \gamma$, length of developed part hardly stretched any more. This might due to the fact that water in sample was absorbed thoroughly by the paper, and lead could not move further. The length of developed part decreased as the amount of lead decreased. If the amount of lead was less than $0.5 \gamma$, stain was hard to distinguish from the color of background.

The relation between the length of developed part $(l \mathrm{~mm})$ and the amount of lead $(m \gamma)$ was shown in the following equations.

$$
\begin{array}{ll}
\text { width of filter paper, } 4 \mathrm{~mm}: & l=10 \log m+9 \\
\text { width of filter paper, } 2 \mathrm{~mm}: & l=11 \log m+14
\end{array}
$$

It was thought from these results that filter paper of $2 \mathrm{~mm}$ in width was a little more convenient than that of $4 \mathrm{~mm}$ in width for determination of lead.

\section{DETERMINATION BY AREA}

When common filter paper was used instead of narrow paper, there was a close correlation between amounts of lead and areas of developed part (Fig. 2).

The area of developed part extended as the amount of lead increased.5) When amount of lead exceeded $50 \gamma$, colored area scarcely extended. This was explained in the similar way as in the length of developed part. As far as the amount of lead remained below $50 \gamma$, area of stained part diminished with the decrease of lead, though the decrease of color concentraion was not so conspicuously. This showed that lead was absorbed on the filter paper selectively 


\section{RAPID DETERMINATION OF LEAD}

and rapidly.6) If amount of lead was below $1 \gamma$, area of colored part reduced no more, and spot became undiscernible from the background.

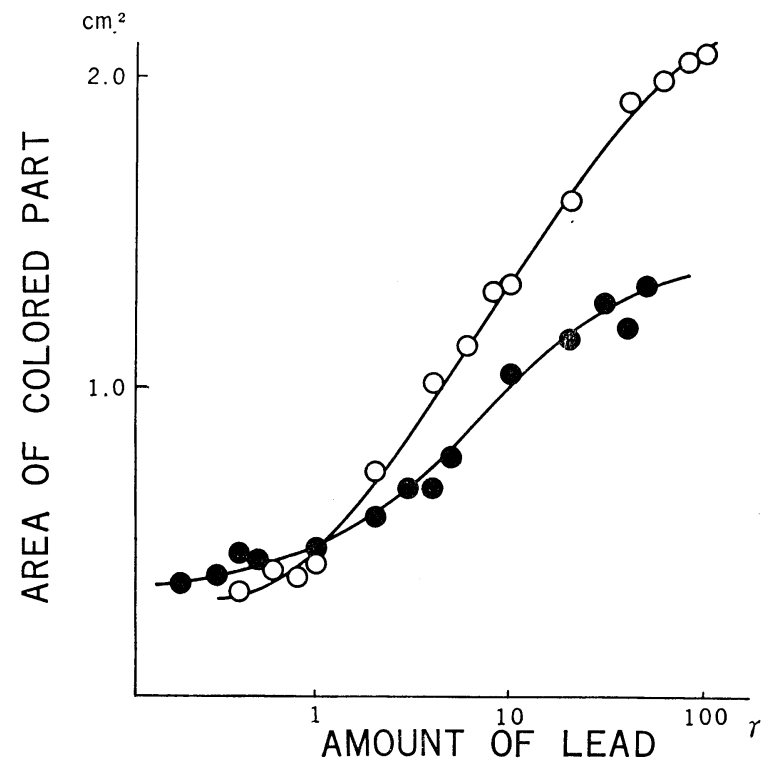

Fig. 2. Relation between the amount of lead and area of colored part.

The relation between area of colored spot $\left(s \mathrm{~cm}^{2}\right)$, and amount of lead $(m \gamma)$ was shown in following linear equations.

$$
\begin{array}{ll}
\text { Amount of sample, } 10 \mu 1 ; & s=0.9 \log m+0.45 \\
\text { Amount of sample, } 5 \mu 1: & s=0.55 \log m+0.4
\end{array}
$$

In these equation, the figures 0.9 and 0.55 showed the incrination of lines.

Fig. 3 was obtained when developed paper were dealt with the densitometer The densitometer shows also the products of concentration and areas of spots.
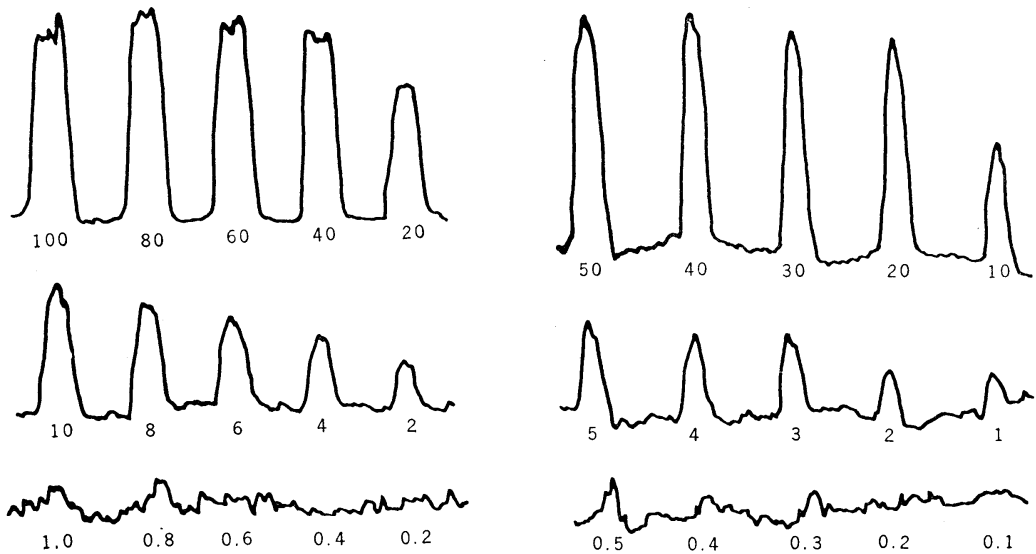

Fig. 3. Densitogram of colored spot dealted with densitometer for filter paper. Numerals indicate the amount of lead $(\boldsymbol{r})$. 


\section{N. HARA}

These products were represented as the counting numbers. If these counting numbers were plotted against the amounts of lead, the calibration curve of lead was obtained (Fig. 4). From Fig. 4, the following equation was obtained,

$$
\mathrm{C}=22 \log m-10
$$

where $m$ was the amount of lead, and $\mathrm{C}$ was the counting number.

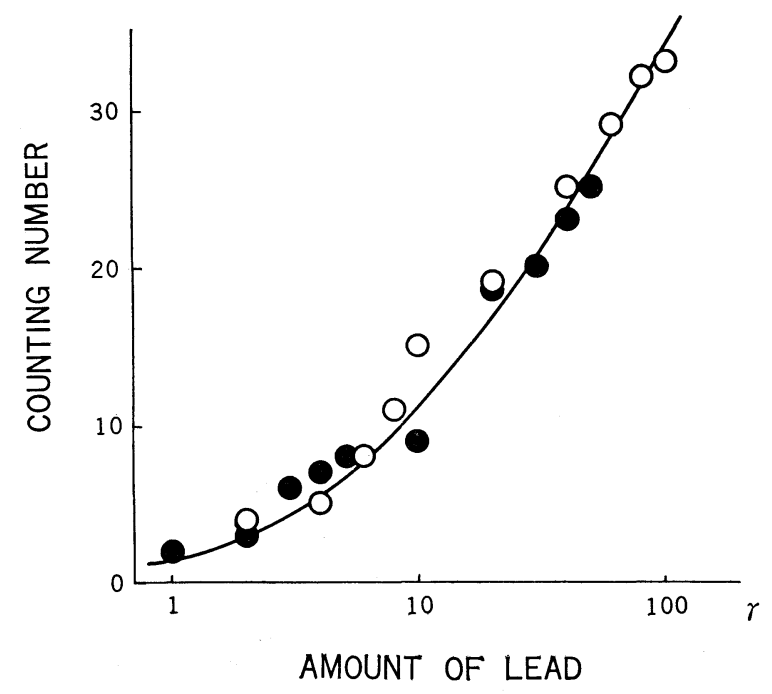

Fig. 4. Calibration curve of lead obtained by using densitometer.

\section{LEAD IN SOLID STATE}

Lead fume and litharge dust captured on the filter paper were dealt in following order.

1. Dissolving them by spraying $2.5 \mathrm{~N}$ nitric acid on the filter paper (Fig. 5),

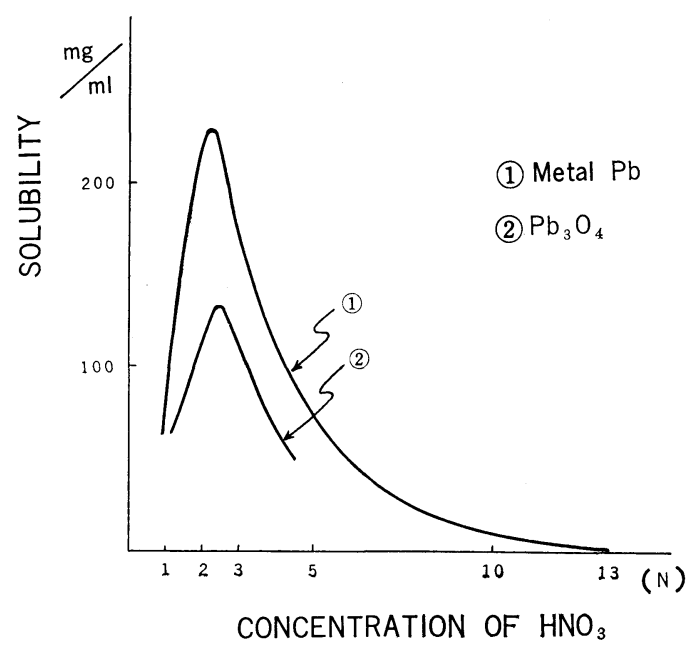

Fig. 5. Solubility of lead compounds in nitric acid. 


\section{RAPID DETERMINATION OF LEAD}

2. Neutralizing the paper in ammonia gas,

3. Heating and drying to remove retained ammonia gas,

4. After these processes, the paper was developed in the same procedure as that of lead nitrate.

The previous method for determination of lead nitrate solution was also tried for the determination of these samples. The filter paper was treated with nitric acid in beaker, in order to dissolve lead particles on the filter paper. This acid solution of lead was spotted on the filter paper and developed. The result was satisfactory. In this case, however, solution should be evapolated and concentrated to about $1.0 \mathrm{mg} / \mathrm{ml}$ before spotting. Spread of acid solution on the filter paper was faster than that of neutral solution.

\section{DISCUSSION}

\section{(1) Diphenylcarbazide as Reagent}

Diphenylcarbazide reacts with lead very sensitively. In addition, its alcoholic solution is colorless and transparent. Diphenylcarbazide and its alcoholic solution, however, are oxydized in air and become to diphenylcarbazone gradually. Diphenylcarbazone is pink-colored. Moreover, alcoholic solution of diphenylcarbazide is red in alkali solution. An adequate control is necessary to prevent the formation of diphenylcarbazone.

\section{(2) Solvent}

Amount of excessive diphenylcarbazide must be as small as possible, because the faint color developed by the oxidation of this reagent sometimes interfere the determination. Ethanol is the most suitable solvent among various alcohols. Methanol is not so suitable, because it evaporates so quickly though it has the highest solubility for diphenylcarbazide. The alcohols above propanol have small solubility, and spots are faint.

\section{(3) Effect of Ammonia Gas}

Time of exposure to ammonia gas must be shorter than about 45 minutes. If more time elapses, background becomes darker. Color on paper fades if exposing time is longer than 10 hours. After development is completed, ammonia gas must be removed thoroughly. The paper is recommended to be dried at $130^{\circ} \mathrm{C}$. Color of background become deeper if the paper is dried above or below $130^{\circ} \mathrm{C}$.

\section{(4) Spraying}

Amount of reagent used is hard to keep constant if it is added by spraying, but this process is superior in uniformity of developed color. If the filter 


\section{N. HARA}

paper is previously dipped in the reagent, uniformity of color is very poor, red ring appears and color of background becomes deeper.

\section{(5) Durability of Color}

The colored spots are formed when the filter paper is inserted in ammonia gas, as mentioned above. The author treated these colored spots in following manners :

(a) Leaving as it is (the paper contains ammonia gas),

(b) Washing with water,

(c) Washing with ethanol,

(d) Drying for 30 minutes at $130^{\circ} \mathrm{C}$,

(e) Drying for 30 minutes at $130^{\circ} \mathrm{C}$ and dipping in liquid paraffine.

In the experiment (a) the developed spot faded in several days gradually and background color became deep rapidly. In (b) and (c) the greater parts of developed substances were lost by washing and spots spread somewhat. In (d) and (e) developed spots were very stable without change of the background color for several months.

\section{(6) Effect of Dipping in Liquid Paraffine}

The process (e) is superior to (d) in two points. First, it exceeds in the stability of color against oxidation. The other point is increase of contrast between developed spot and background. But, there is little difference in color durability between (d) and (e), if ammonia gas are removed thoroughly. In addition, dipped paper is apt to become dirty, making determination of lead difficult. So, the process (d) is the most suitable for determination of lead in practise.

\section{References}

1) Welcher, F. J. (1947). Organic Analytical Reagents, p. 439. D. Van Nostrand Co. Inc., New York.

2) Feigl, F. (1960). Spot Tests in Inorganic Analysis, 6th Ed., p. 72 . Elsevier Publishing Co., Amsterdam.

3) Amdur, M. O. and Silverman, L. (1954) A. M. A. Arch. Ind. Hyg. 10, 152.

4) Quino, E. A. (1959) Am. Ind. Hyg. Assoc. J. 20, 134.

5) Ito, Y. (1963) Kogyo Kagaku Zasshi. 66, 194. (in Japanese)

6) Pollard, F. H. and McOmie, J. F. W. (1953). Chromatographic Method of Inorganic Analysis, p. 51. Butterworths, London. 